\title{
Lidar measurements validation under coastal condition
}

\section{Validación de mediciones con Lidar en zona costera}

\author{
Pedro Alvim A. Santos ${ }^{1 *}$, Yoshiaki Sakagami², Reinaldo Haas ${ }^{1}$, Júlio C. Passos ${ }^{1}$, Frederico \\ F. Taves ${ }^{3}$ \\ 1. Dept. of Mechanical Engineering, Federal University of Santa Catarina, Florianópolis, Brazil \\ 2. Dept. of Health and Science, Federal Institute of Santa Catarina, Florianópolis, Brazil \\ 3. Tractebel Energia S.A. (GDF Suez), Florianópolis, Brazil \\ $\left.{ }^{*}\right)$ E-mail: pedroasantos@lepten.ufsc.br
}

Received / Recibido: 19/05/2015 Accepted / Aceptado: 26/05/2015

DOI: $10.7149 /$ OPA.48.3.193

\begin{abstract}
:
This study aims to validate measurements of a wind Doppler Lidar profiler installed in a wind farm at the Brazilian coastline. An experimental setup was deployed in Pedra do Sal site, located inside a $18 \mathrm{MW}$ wind farm at the northeast coast of Brazil. The objective is to use wind data from a $100 \mathrm{~m}$ meteorological tower as reference and correlate wind profile lidar data to analyze deviations and site-specific effects. The measurement campaign covered a one-year period. Results show a good correlation between lidar and tower, with a correlation of $\mathrm{R}^{2}=0.97$. However, there is a non-linear behavior of the bias along the wind speed range. The calculated bias for the four analyzed levels is confirmed with a negative skewness and high kurtosis. In conclusion, the studied lidar profiler presented a good correlation with the reference data, but with significant deviations for wind energy applications. The source of the observed bias behavior is still to be better understood.
\end{abstract}

Key words: Wind Energy, Wind lidar, Validation, Bias analysis.

\section{REFERENCES AND LINKS / REFERENCIAS Y ENLACES}

[1] IEA, Ground-based vertically profiling remote sensing for wind resource assessment, International Energy Agency, 2013.

[2] A. Albers and A.W. Janssen, Evaluation of Windcube, Deutsche WindGuard Consulting GmbH, 2008.

[3] CRES, Test Report 546-01B: Operation of the Windcube V2 lidar at CRES Test Station, Centre for Renewable Energy Sources and Saving, 2011.

[4] J. Gottschall and M. Courtney, Verification test for three WindCubeTM WLS7 LiDARs at the Høvsore test site, RISO National Laboratory for Sustainable Energy, 2007.

[5] B. Cañadillas, A. Westerhellweg, and T. Neumann, "Testing the Performance of a Ground-Based Wind LiDAR System: One year intercomparison at the Offshore Platform FINO1," DEWI Magazin, vol. 38, Feb. 2011, pp. 58-64.

[6] Y. Sakagami, P.A.A. Santos, R. Haas, J.C. Passos, and F.F. Taves, "Wind shear assessment using wind LiDAR profiler and sonic 3D for wind energy applications - Preliminary Results," Proceedings of World Renewable Energy Congress XIII, London: 2013.

\section{Introduction}

New challenges are faced with the increasing use of lidar technology in wind energy applications, with clear advantages in resource assessment and power performance measurements. The usage of lidars in wind farms should always be validated with traditional traceable technologies such as cup anemometers and wind vanes, when possible. With many field experiences, best practices in ground-based lidars can be followed in order to achieve reduce measurement uncertainties [1]. 
The present study aims to validate measurements of wind Doppler lidar with a reference meteorological mast to analyze deviations and site-specific effects. Preview studies have already evaluated the performance of lidar profilers under distinct conditions [2-4], but few field experiments used large datasets, as one-year period, to account for seasonal effects and equipment reliability [5].

\section{Methodology}

\section{2.a. Test Site}

This work is part of a one-year measurement campaign, where the lidar was installed inside an operating wind farm along with a $100 \mathrm{~m}$ meteorological mast and operated for a one-year period, from September 2013 to August 2014.

The test site is located in the northeast coast of Brazil at Pedra do Sal Wind Farm (2049'39.17'S, $41^{\circ} 42^{\prime} 38.31^{\prime \prime} \mathrm{W}$ ), with a total installed capacity of $18 \mathrm{MW}$. Twenty wind turbines, model E-48 with 0.9 MW of rated power, are aligned with the shoreline facing the prevailing wind.

Fig. 01 shows a representation of the test site with the wind lidar (2049'34.57"S, 41042'36.38”W) and meteorological tower installed $\left(2^{\circ} 49^{\prime} 22.50^{\prime \prime} \mathrm{S}, 41^{\circ} 42^{\prime} 50.20^{\prime \prime} \mathrm{W}\right)$ in the wind farm. The wind Doppler lidar with a $500 \mathrm{~m}$ range is installed $150 \mathrm{~m}$ upwind the wind turbine array. Both the lidar and the met tower, which is used as reference data, are located $300 \mathrm{~m}$ away from the shoreline and $565 \mathrm{~m}$ apart from each other.

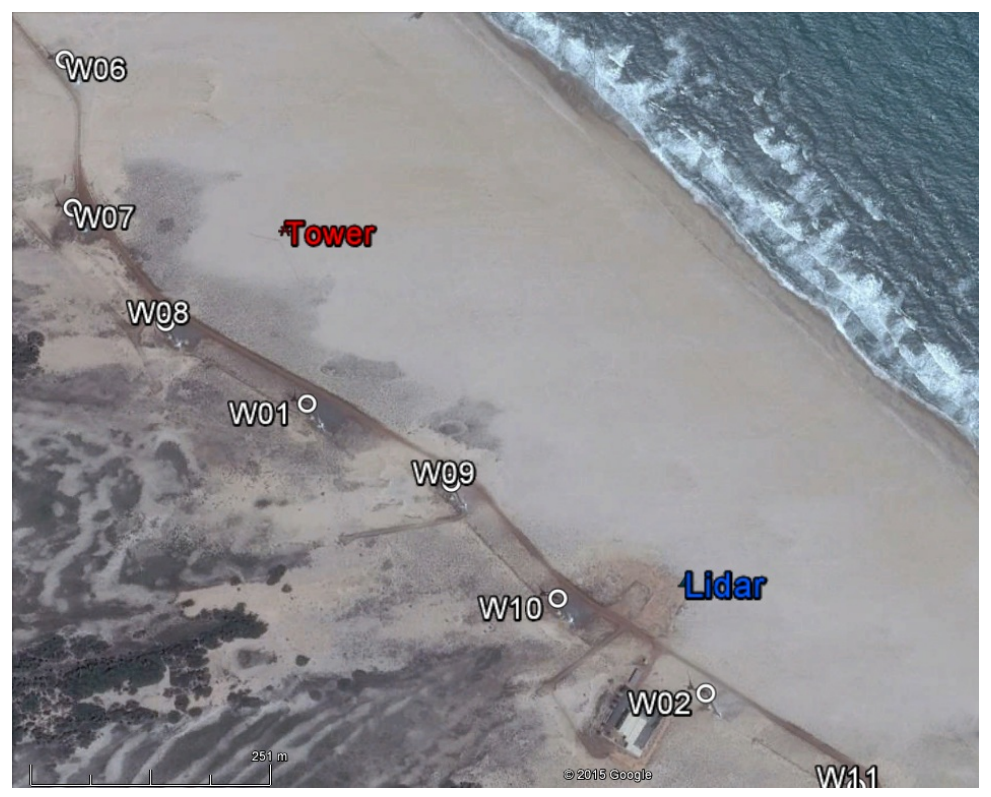

Fig. 1. Pedra do Sal wind farm with wind lidar and meteorological tower

\section{2.b. Equipment and Method}

The meteorological tower is used as reference for the wind lidar measurements validation (Fig. 02a). Wind speed data for this study is measured with Thies P6101H first-class calibrated cup anemometers at $40 \mathrm{~m}, 60 \mathrm{~m}, 80 \mathrm{~m}$ and $98 \mathrm{~m}$. At the highest point of 100m, the tower also has a RM Young 81000 3D sonic anemometer. The met tower layout follow the International Electrotechnical Commission (IEC) standards $[3,4]$.

The installed wind Lidar is the WindCube8 from Leosphere, used to measure wind speed, standard deviation and wind direction at 26 adjustable levels from $40 \mathrm{~m}$ to $500 \mathrm{~m}$ height (Fig. 02b). The horizontal and vertical components of the wind speed at each level are measured based on the velocity azimuth display (VAD) technique, with four lines of sight aligned with the cardinal points. 
With a defined setup of 90,000 laser pulses per line of sight, one complete measurement of $360^{\circ}$ takes approximately $6 \mathrm{~s}$ to be completed. The wind data is computed and stored at a 10 -min average basis, as commonly used for wind energy purposes. Therefore, one 10-min wind data uses 100 measured samples for each height.

A measured sample is consider valid if the Carrier-to-noise ratio (CNR), which represents the quality of the laser signal, is higher than a threshold set at $-28 \mathrm{~dB}$. The percentage of valid samples defines a data availability parameter. The study uses only 10 -min data with $100 \%$ of data availability.

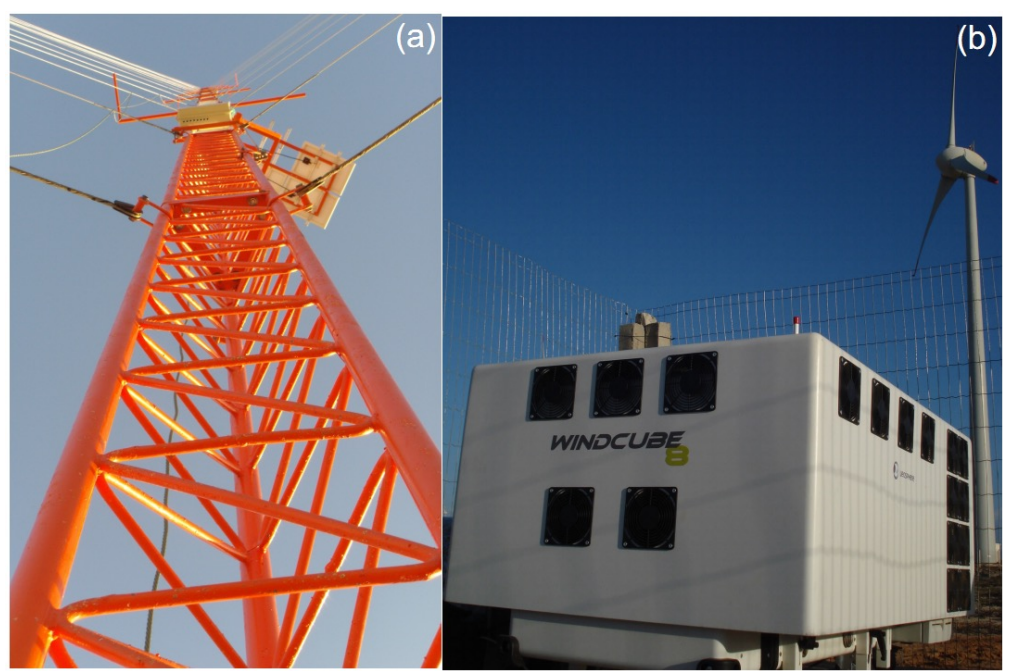

Fig. 2. $100 \mathrm{~m}$ met tower (a) and Wincube8 Lidar (b) operating in Pedra do Sal.

The evaluated wind profile heights in this study are $40 \mathrm{~m}, 60 \mathrm{~m}, 80 \mathrm{~m}$ and $100 \mathrm{~m}$. All wind sectors are considered valid for the comparison. Both met tower and lidar data have time synchronization with a GPS system. Complementary data of temperature and relative humidity from the met tower are not used for a direct comparison with lidar measurements, but were considered in the filtering procedure.

The validation of lidar measurements are based on a direct correlation with the reference data, with a linear regression. The $100 \mathrm{~m}$ 3D sonic wind speed is validated with the $98 \mathrm{~m}$ calibrated cup anemometer.

Along with a random error, given by the dispersion of the correlation, the bias is also calculated, defined as lidar wind speed minus reference wind speed. Results are further investigated with a statistical analysis that considers the skewness and kurtosis of the data distribution.

\section{Results}

\section{3.a.- Lidar Validation}

Fig. 03 presents the validation of wind speed measurements at the met tower, between the 3D sonic at $100 \mathrm{~m}$ and the cup anemometer at $98 \mathrm{~m}$, which presents the consistency of a reference wind speed.

Lidar measurements are validated by a linear regression between the met tower and lidar horizontal wind speed, where results are showed in Fig. 04. It's observed a good correlation for the four analyzed heights, with almost no offset. The $565 \mathrm{~m}$ distance between the instruments could have introduced deviations and the observed dispersion.

Fig. 05 shows the wind roses both from the reference (a) and the lidar (b). The lidar wind direction presented an average deviation of $13.2^{\circ}$ the met tower. Alignment issues and also the distance probably influenced the result. It's clear the strong influence of wind coming from the ocean, characterizing the Brazilian northeast trade winds [6]. It's also noticeable the site's high wind speed values, a characteristic usually not present in other validation studies $[3,4]$. 


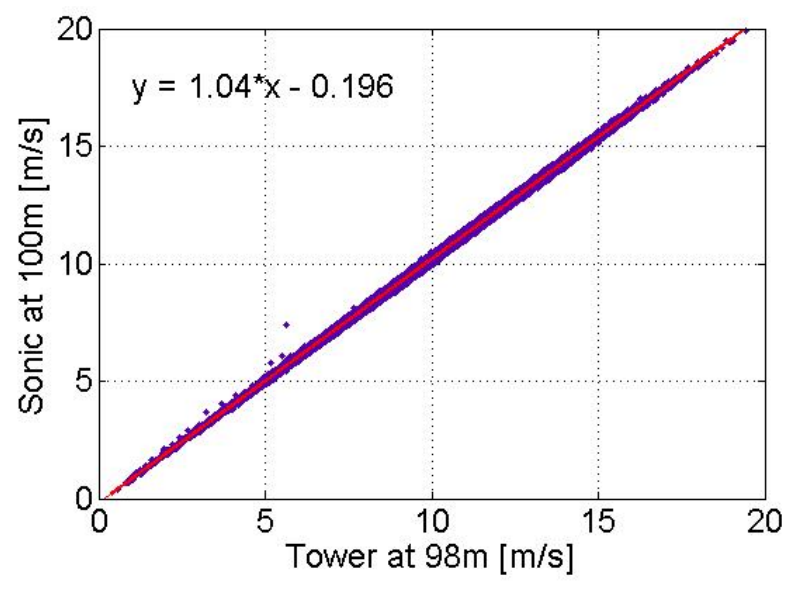

Fig. 3. 3D Sonic anemometer wind speed correlation.
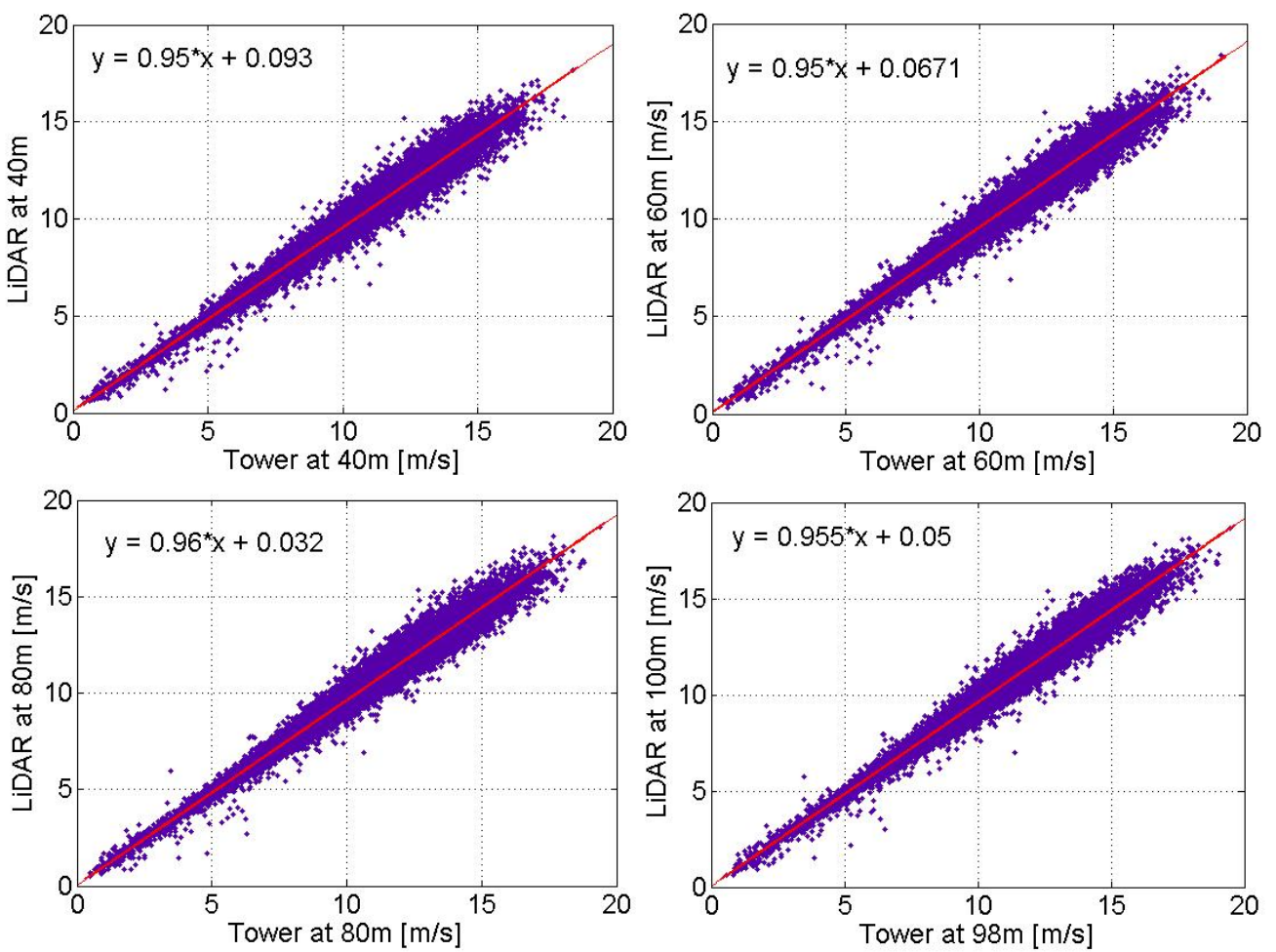

Fig. 4, Tower and lidar one-year wind speed correlation for all analysed heights.
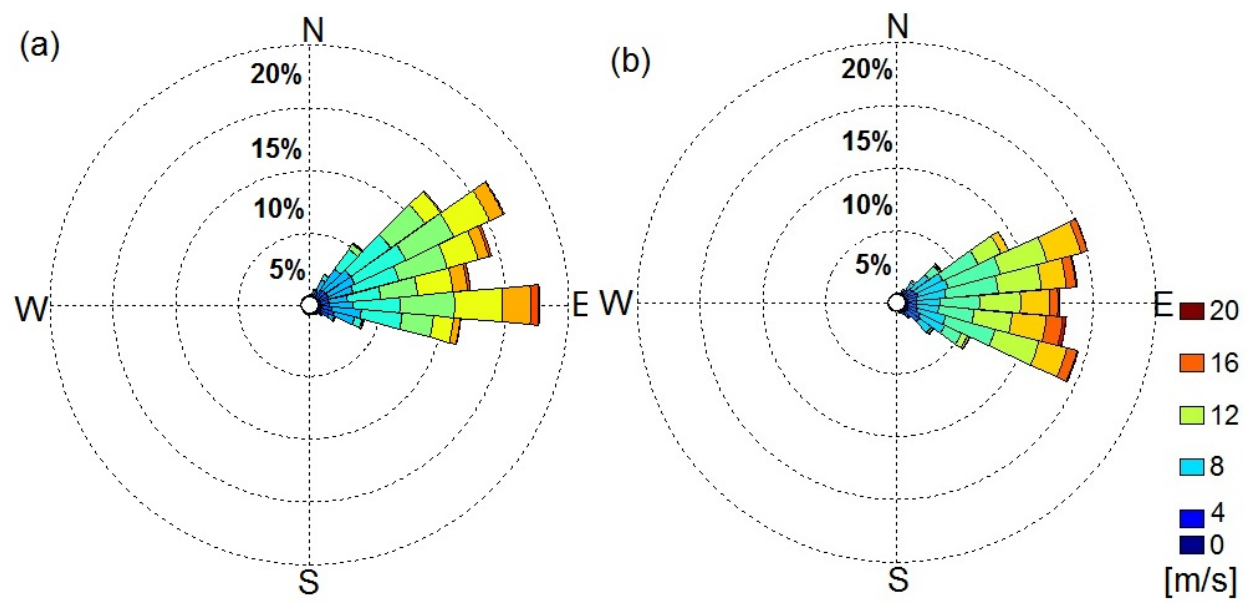

Fig. 5. Tower(a) and lidar (b) one-year wind direction comparison at $100 \mathrm{~m}$ height. 


\section{3.b.- Bias analysis}

Fig. 06 shows the results of wind speed bias of lidar measurements divided in $0.5 \mathrm{~m} / \mathrm{s}$ wind speed bins. It's clear the lidar underestimation of the wind speed when compared with the reference. Moreover, the bias tends to increase for higher wind speed values. This behavior is observed for all four lidar heights and interestingly with really close bias values. Bias standard deviations are not significant and therefore not represented in the plot.

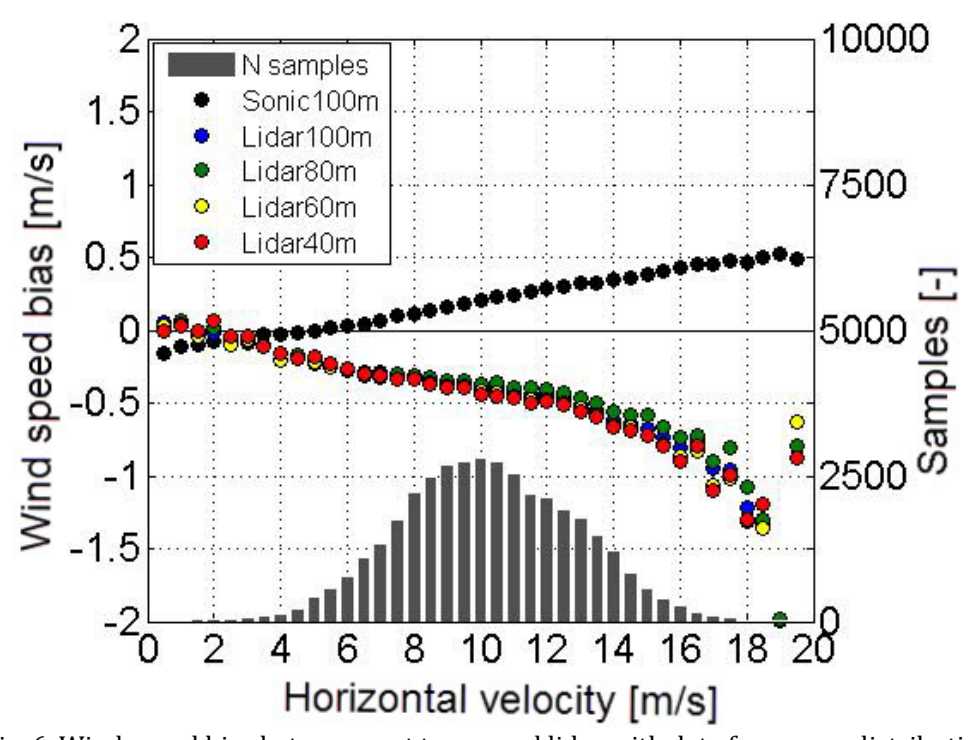

Fig. 6. Wind speed bias between met tower and lidar with data frequency distribution.

It's also observed a non-linear dependence of the bias with the horizontal velocity, which difficult the bias correction. The measured lidar errors are higher than the specified by the manufacturer, which has an equipment accuracy of $0.3 \mathrm{~m} / \mathrm{s}$. At around $10 \mathrm{~m} / \mathrm{s}$, the mean bias is $0.5 \mathrm{~m} / \mathrm{s}$, considered significant for wind energy applications.

The lidar error for higher values of wind speed is even larger, but don't have a large number of samples to be consistent. The sonic anemometer presented an overestimation for high wind speeds when compared with the reference, probably due to tilting and tower shading.

The increasing bias was already measured in other validation studies [3], being mainly related with measurements in complex terrain. However, the studied site is located in the shoreline with low terrain roughness and obstacles, hence raising questions about the source of the bias magnitude and behavior.

The bias statistical behavior is further analyzed in Tab. 01 . The four lidar levels are presented along with the sonic anemometer validation.

As previously showed, the lidar presents a negative average bias. This underestimation behavior, as well as the tendency observed in Fig. 06, is confirmed by the negative skewness and high kurtosis for the four analyzed heights.

\begin{tabular}{|c|c|c|c|c|c|}
\hline Height [m] & $40 \mathrm{~m}$ & $60 \mathrm{~m}$ & $80 \mathrm{~m}$ & $98 \mathrm{~m}$ & Sonic \\
\hline $\operatorname{Bias}[\mathrm{m} / \mathrm{s}]$ & -0.44 & -0.43 & -0.38 & -0.41 & 0.21 \\
\hline Skewness [-] & $\begin{array}{l}-0.49 \\
\end{array}$ & -0.44 & -0.18 & -0.43 & 0.00 \\
\hline Kurtosis [-] & 5.77 & 5.50 & 5.45 & 6.04 & 2.93 \\
\hline $\operatorname{RMSE}[\mathrm{m} / \mathrm{s}]$ & 0.62 & 0.61 & 0.57 & 0.57 & 0.25 \\
\hline Slope [-] & 0.94 & 0.95 & 0.96 & 0.95 & 1.04 \\
\hline $\mathbf{R}^{2}[-]$ & 0.97 & 0.97 & 0.97 & 0.98 & 1.00 \\
\hline
\end{tabular}

The sonic anemometer validation is confirmed by a symmetric and Gaussian distribution, showed by the zero value skewness and kurtosis of almost 3.0. Further parameters confirm the good quality of reference data, with low root mean square error (RMSE) and unitary correlation coefficient. 


\section{Conclusions}

The present paper validates the one-year measurement campaign of a Windcube8 Doppler lidar installed in an operating wind farm in the northeast coast of Brazil. A $100 \mathrm{~m}$ meteorological tower was used as reference data. The horizontal wind speed correlation presented good results, with an average $\mathrm{R}^{2}$ of 0.97 .

A systematic error was spotted in the lidar measurements for the four analyzed heights, with an average offset $-0.42 \mathrm{~m} / \mathrm{s}$, higher than the equipment accuracy. This significant bias tends to increase for higher wind speed values with a non-linear dependency. This behavior is confirmed by a negative skewness and high kurtosis.

The results show an unexpected bias behavior for a coastal condition with low terrain roughness, since previous studies showed a similar bias tendency only at sites with complex terrain. Therefore, further inputs are necessary to clarify the sources of such deviations.

\section{Acknowledgements}

This study is supported by the Brazilian Electricity Regulatory Agency (ANEEL) and Tractebel Energia S.A. (GDF Suez). 